\title{
HISTORICAL SENTIENT - BUILDING INFORMATION MODEL: A DIGITAL TWIN FOR THE MANAGEMENT OF MUSEUM COLLECTIONS IN HISTORICAL ARCHITECTURES
}

\author{
F. M. La Russa ${ }^{1}$, C. Santagati ${ }^{1, *}$ \\ ${ }^{1}$ Department of Civil Engineering and Architecture (DICAR), Università degli \\ Studi di Catania, Via Santa Sofia n. 64,95125 Catania, Italy - federico.larussa@phd.unict.it / cettina.santagati@dau.unict.it
}

Commission IV, WG VI/9

KEY WORDS: Digital Twin, Historical Architecture, Artificial Intelligence, Decision Support System, Architectural Survey, Preventive conservation

\begin{abstract}
:
This paper investigates the application of the Digital Twin approach to get a Sentient building able to acquire the ability to perceive external inputs and develop strategies to support its management and/or conservation. The experimentation foresees the integration of an H-BIM model with a Decision Support System based on Artificial Intelligence (in this case Machine Learning techniques) for the management of museum collections in historical architectures. The innovative aspect of this methodology resides in the change of paradigm regarding the relations between the historical building under consideration and the professional figures who deal with the management, conservation and architectural restoration. This work tries to contextualize the novel HS-BIM methodology within the theoretical discussion of the disciplines mentioned above and to participate in Digital Twin's debate. HS-BIM can be seen as a possible path that leads to creating digital twins for cultural heritage. The reflection inspired by this experience aims to revise the concept of Digital Twin as a parallel/external digital model in favour of an artificial evolution of the real system augmented by a "cognitive" apparatus. In this vision, thanks to AI application, future buildings will be able to sense "comfort and pain" and learning from their own life-cycle experience but also from that one of elder sentient-buildings thanks to transfer learning already applied in AI's fields.
\end{abstract}

\section{INTRODUCTION}

The Anthropocene age is strongly characterized by disruptive changes that are impacting the relationship between humans and technology. Among these, the tremendous potentialities linked to AI (Artificial Intelligence) applications in a variety of fields are increasingly visible. With specific reference to AEC (Architecture Engineering Construction) field and to historical architecture domain, the adoption of advanced and innovative digital workflows can advantage and optimize preservation activities. Among all the buildings that fall under heritage preservation, there is a specific typology to which this research is mainly addressed: museums hosted in historical architectures. In this case, the issue of heritage preservation has to consider both the historical values of the building - the container - and the peculiarities of the collections - the content. For instance, the maintaining of the optimal environmental conditions for museum collections is critical as well as the proper conservation of the historical building. The study deals with the experimentation of innovative methodologies that allow advanced management of museum collections, hosted in a historical building, through the development of a DSS (Decision Support System) that uses ML (Machine Learning) to implement effective conservation strategies. The aim is to investigate the application of DT (Digital Twin) approach to get a Sentient building able to acquire the ability to perceive external inputs and develop strategies to support its management and/or conservation. The formulation of a novel methodology - namely HS - BIM (Historical Sentient - Building Information System) - for historical building documentation, management, and conservation is proposed. As case study, it has been chosen the university museum MuRa (Museo della
Rappresentazione) in Catania. The museum is hosted in villa Zingali Tetto, a historical building realized in 1930 which houses a collection of engravings and design drawings by architects and etchers. In particular, the experimentation focuses on the management of the thermo-hygrometric conditions for the preventive conservation of the collection and the museum rooms. Our contribution is structured as follows: after the review of the state of the art and the focus on the problem definition, we describe the HS-BIM definition; then the related methodology is illustrated; HS-BIM approach is shown concretely through the chosen case study on MuRa (Museo della Rappresentazione) in Catania. Finally, in the conclusions some reflections on the adoption of the methodology and further developments will be shown.

\section{RELATED WORKS}

The impact of Industry 4.0 on AEC sector is increasingly growing, we are witnessing continuous experimentation and innovations that have appeared in the industrial and manufacturing sector and are gradually spreading to new buildings construction and the built environment. In the last decades, the main focus in AEC has been mainly on Energy Management driven by the integration of intelligent technologies in building systems (Wong et al., 2005). There has been an evolution in the concept of Building Automation System: from Automated Buildings, able to show key performance indicators; to Smart Buildings, able to analyze energy consumers (Clements-Croome, 2004); up to Cognitive Buildings, able to learn behavior (Ploennigs and Schumann, 2017). Indeed, the concept of CB (Cognitive Building) is integrated with sensing technologies, distributed intelligence

* Corresponding author 
and IoT (internet of things) and is strictly linked with the concept of DT (Digital Twin). Since Michael Grieves coined the word DT in 2002 in the context of manufacturing (Grieves, 2019), this concept has been leveraged in different fields achieving different levels of maturity. An effective definition of DT is given by Bolton et al as "a dynamic virtual representation of a physical object or system across its lifecycle, using realtime data to enable understanding, learning and reasoning" (Bolton et al., 2018; p. 783). The integration of AI with IoT and BIM (Building Information Modeling) technologies (Pasini et al., 2016) will give DT the ability to assimilate, analyze, simulate, predict, prescribe and act with minimal human involvement as envisioned by Bien et al (Bien et al., 2002; Zuchker et al., 2018).

In literature we find several attempts in the definition of the DT level of maturity (Sophistication). A first definition is given by Madni et al (Madni et al., 2018) and regards the industry sector in general: Level or Pre-Digital Twin (virtual system model with an emphasis on technology/technical-risk mitigation); Level 2 or Digital Twin (virtual system model of the physical twin exists); Level 3 or Adaptive Digital Twin (virtual system model of the physical twin with adaptive UI); level 4 Intelligent Digital Twin (virtual system model of the physical twin with adaptive UI and reinforcement learning). As for Built environment, Simon Evans (Evans, 2019) proposes six levels: Level 0 or Reality capture (e.g. point cloud, drones, photogrammetry, or drawings/ sketches); Level 1 or 2D map/system or 3D model (e.g. object-based, with no metadata or BIM); Level 2 or Connect model to persistent (static) data, metadata and BIM Stage 2 (e.g. documents, drawings, asset management systems); Level 3 or Enrich with real-time data (e.g. from IoT, sensors); Level 4 or Two-way data integration and interaction; Level 5 or Autonomous operations and maintenance. To date, these concepts have found limited application in historical heritage and museums domain, even if the Natural History Museum in London has recently embraced this technology (Richardson, 2020). Many institutions have applied H-BIM (Historical Building Information Modeling) and in parallel there has been an increase of computation techniques in architecture thanks to the development of user-friendly VPL (Visual Programming Language) such as Grasshopper, Dynamo, Node Red, Ardublock, NETLab Toolkit, ReactiveBlocks, GraspIO, Wyliodrin. The flexibility of these computational tools allows us to enrich H-BIM models with new concepts, definitions, layers of actions and knowledge, as well as to manage, catalog and reorder the data and the different relationships contained in the models (Argiolas et al., 2015; Giovannini, 2017; Tono et al., 2019). In the management of historical buildings with museum functions, applications using DSS have become increasingly frequent in recent years. These technologies are often used together with WSN (Wireless Sensor Network), which allow constant and real-time monitoring of all the significant parameters for the needs of the museum layouts and the architectures that contain them. The project of the Sala dei Cinquecento at Palazzo Vecchio in Florence (Viani, 2014), the ones on Palazzo della Civiltà Italiana in Rome (Trento et al., 2019) and the Museo Egizio in Turin (Calvano et al., 2020) can be considered remarkable examples. ML applications in Architecture and Construction were already being developed at the time of the first CAD applications in the 1960s (Wright Steenson, 2017). They were intended to experiment with direct human-computer interaction to facilitate, optimize and develop the design process. There are several cases in which neural networks have been trained for design purposes in the construction sector, such as the work carried out at the University College of London, where the possibility of training a robotic arm to make woodwork components has been examined (Brugnaro and Hanna, 2017). In other words, the aim is to develop a system for evaluating the rooms of a building using datasets made from the assessments of users in many other buildings to understand which recurring patterns ensure conditions of comfort (Davis, 2016; Kim, 2018). There are experiments that also concern the classification of different types of environments using neural networks (Tono et al., 2019; Peng et al., 2017).

\section{HS-BIM}

The HS-BIM (Historical Sentient - Building Information Modeling) definition proposed in this research work draws on the considerations made on the above mentioned DT maturity levels, focuses on historical buildings preservation actions and is projected towards the level 5 'Autonomous operations and maintenance' (Evans, 2019)/level 4 'Intelligent Digital Twin' (Madni et al., 2019). Indeed, it envisions the implementation of H-BIM models performances by applying AI techniques, specifically ML. Therefore, we can define HS-BIM (La Russa, 2019a) as a BIM model that perceives the external and internal inputs of the historical building it represents, recognizes the manifestations of degradation and reports them, elaborates the inputs thanks to learning mechanisms and autonomously makes choices related to its preservation strategies (Fig. 1).

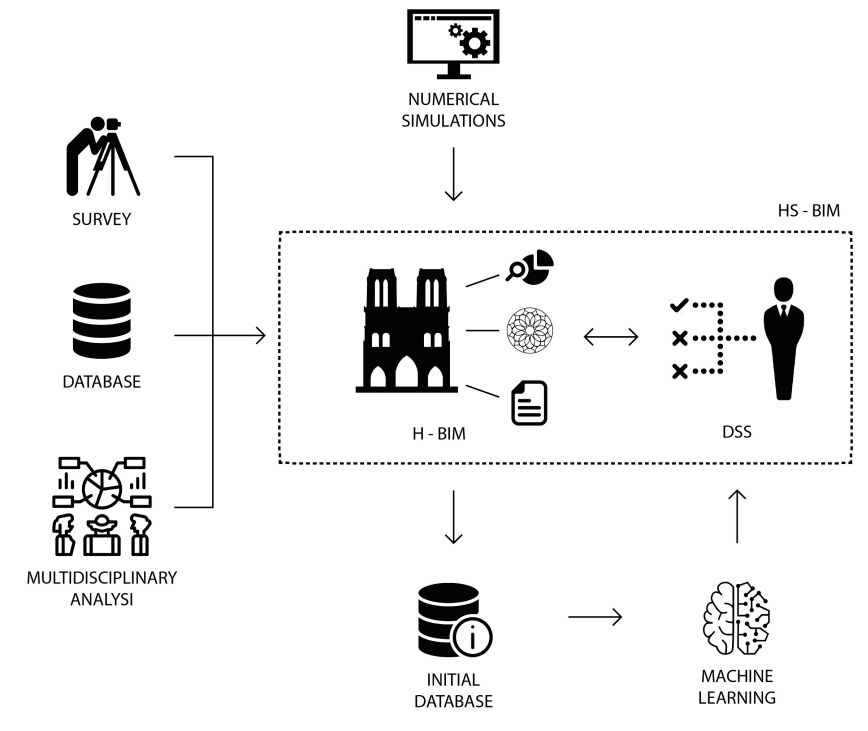

Figure 1. HS-BIM Workflow 
The innovative aspect of this methodology resides in the change of paradigm regarding the relations between the historical building and the professional figures who deal with its management, conservation and restoration. The analogy between a human being and a building, well established in the disciplines of conservation and architectural restoration, is based on a reinterpretation of architecture as a living organism that goes through a life cycle, has a certain state of health and requires rehabilitation therapies in the presence of diseases (Marconi, 1993).

It is possible to identify similarities between the physical and behavioral aspects highlighted in living beings and the techniques used in BIM-based methodologies (Tono, 2018). For example, the ability to receive real-time data from different kinds of diagnostic sensors located in strategic points of the building can be envisioned as a peripheral nervous system that receives external inputs. In the presence of this condition, it is possible to compare the building to the corpus (as it is often called in the medical approach) while its animus (its nervous system) is its virtual prosthesis, i.e. the HBIM model. In this configuration, despite the complexity of the processes put in place, the model does not already have an active behavior. With the creation of a DSS based on Machine Learning mechanisms, the DT of the building - namely the HS-BIM model - assumes a synthetic behavior in the processing of inputs, thus becoming Sentient. The training process is supervised (there are scenarios controlled by the designer) and each solution will be "an experience" for the building from which to learn. In this sense we could find also some relations between the learning theory of the psychologist Thorndike (Thorndike, 1905) and ML techniques. Learning in sentient beings generally occurs through the transfer of knowledge from adult individuals or is embedded in the nature of the being. Similarly, the starting training dataset takes the role of the 'teaching adult' and contributes to the constitution of the anima of the HS-BIM model, where ' $\mathrm{S}$ ' stands for 'Sentient' and encompasses the evolution from a passive to an active decision-making model.

\section{METHODOLOGY}

The developed methodology addresses the management of the thermo-hygrometric conditions for the preventive conservation of museum collections in buildings with high historical value. Therefore, after a first step aimed at the 3D digitalization of the building and its semantic modeling in a BIM environment, the following steps are focused on the realization of a DSS to assist the building manager in the decision-making phases related to the conservation of the museum collections and architectural interior spaces. Specifically, the design of the DSS is carried out through a VPL work environment in order to guarantee characteristics such as responsivity, flexibility, and userfriendliness. Furthermore, the DSS is set on AI mechanisms (in particular ML) which, on the basis of a training dataset, recognizes the relationship between a combination of actions and the relative satisfaction of thermo-hygrometric conditions and makes previsions. The methodology is structured as follows:

- 3D digitalization of the historical building by means of instrumental surveys (laser scanners and photogrammetry) and critical analysis of the construction apparatus of the historical building;

- HBIM modeling of the whole building taking into account high LOD for museum rooms under analysis;

- gathering of meteorological data stored by the nearest climate station;

- microclimate analysis of the urban context;

- simplification of the HBIM model into a NURBS model and thermo-technical information enrichment in VPL environment;

- setting out the standard action strategies (already implemented) in relation to the maintenance of museum collections;

- specification of the thermo-hygrometric parameters (prescribed by national regulations) for the conservation of the collections in each museum room;

- gathering of the thermo-technical data collected inside the museum or, in the absence of the latter, creation of a synthetic dataset carrying out specific energy simulations considering the conservation strategies already in use;

- data labeling and filtering to ensure supervised learning of the training dataset;

- training and validation of the ML algorithm.

\section{CASE STUDY}

The adequacy of the approach so far explained has been validated on a cultural heritage building that shows a complex showcase of preservations needs: villa Zingali Tetto in Catania (Fig. 2). Built in 1930, this architecture houses the Museo della Rappresentazione (Museum of Representation) and it is managed by the Department of Civil Engineering and Architecture of the University of Catania (La Russa, 2019b).

The villa has been subject to geometric and spatial surveys (mainly using laser scanners and photogrammetry) and archival researches to reconstruct historical and constructive events. The complexity linked to the many interior environments (small rooms, corridors, staircases) required to carry out a large amount of TLS (Terrestrial Laser Scanning) scans (233) with the aim of covering as much as possible surfaces for each floor (Fig. 3). In this way, it was possible to fully understand the space syntax and expositions of each area of the villa. Several decorated surfaces (as wood and frescos ceilings) and furniture have been acquired by using SFM (Structure from Motion) techniques. Therefore, a HBIM model of the villa has been created according to PointCloud-to-BIM approach (Fig. 4).

This analysis was useful to structure the subsequent energy simulations. As already mentioned, the study has been focused on the conservation issues linked to the collections, with reference to the thermo-hygrometric conditions. Due to the high 

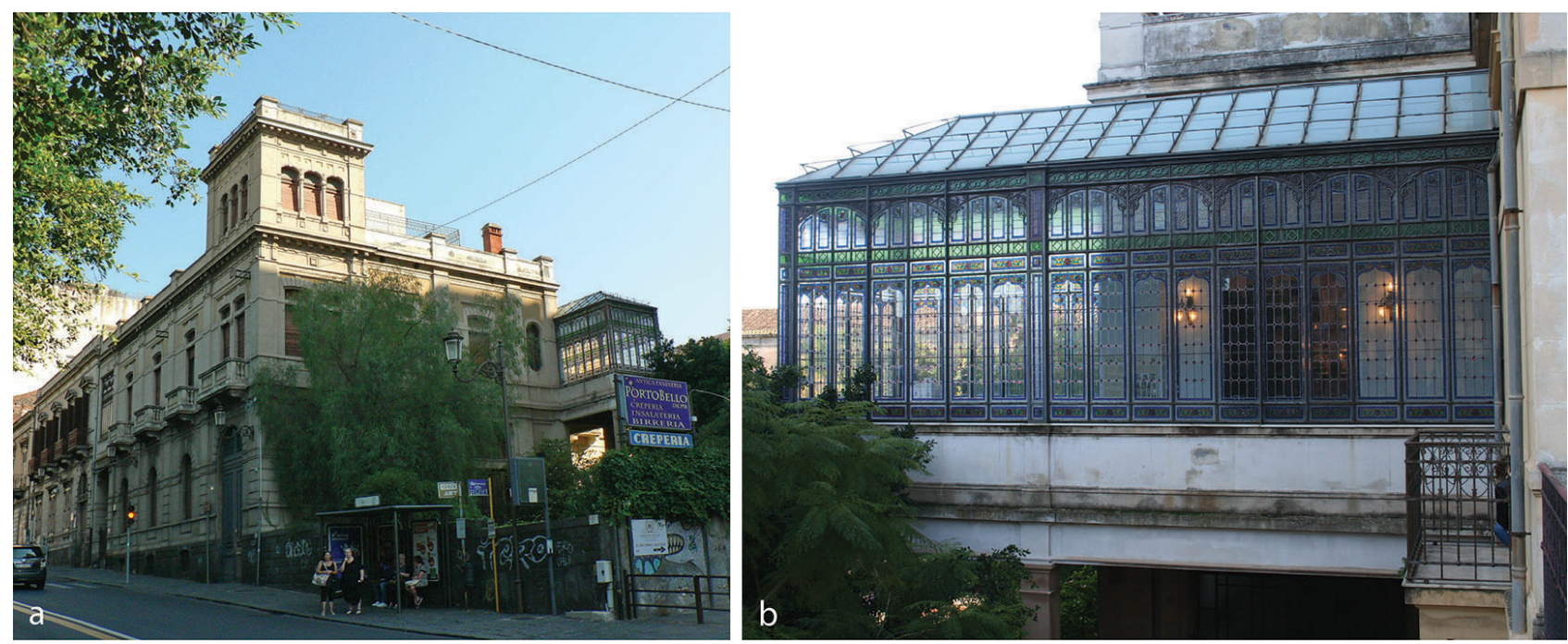

Figure 2. Views of villa Zingali Tetto: a) exterior; b) winter garden made by Salvatore Gregorietti (Palermo 1870 - Palermo 1952)

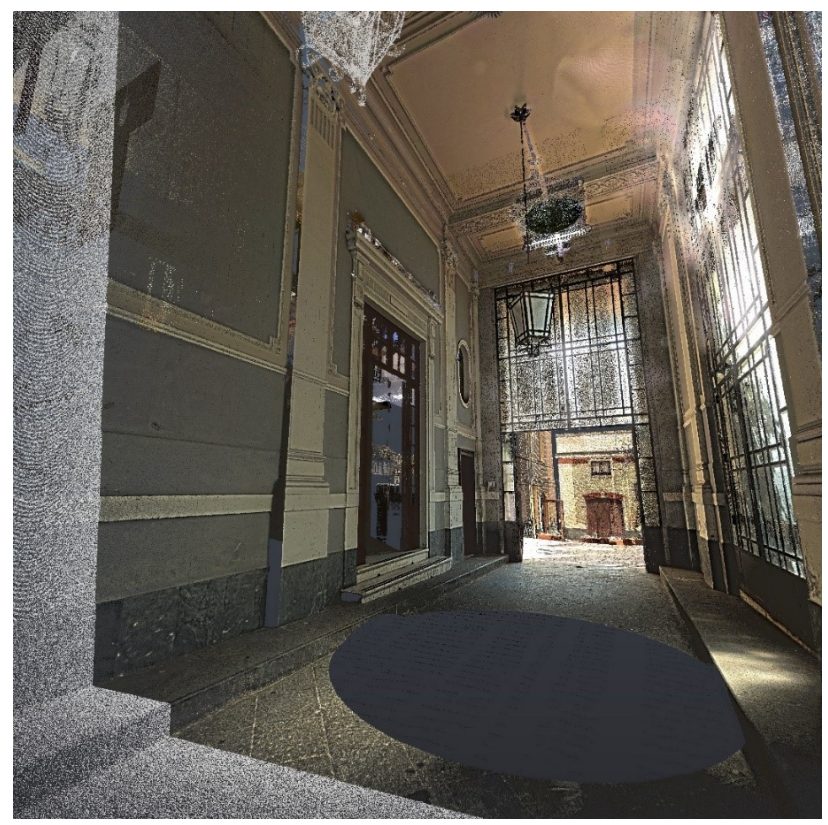

Figure 3. Point Clouds of the entrance atrium.

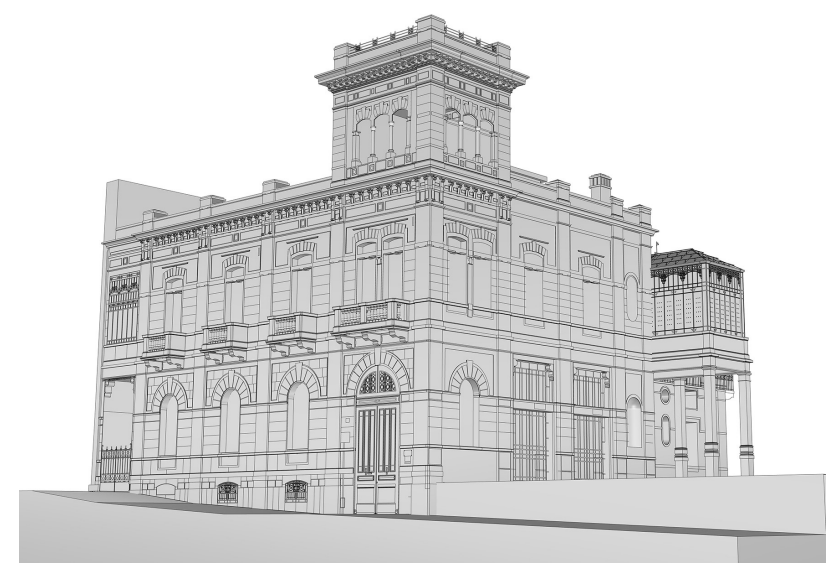

Figure 4. Perspective view of the HBIM model cultural importance of the villa, the planned actions are not invasive and are designed to manage the building through passive strategies (natural ventilation, occupation of the rooms) and the optimization in using existing HVAC (Heating, Ventilation and Air Conditioning) system. For the design of the DSS system, considering all the requirements to take into account, Machine Learning (ML) algorithms linked to multivariate linear regression are applied. Indeed, these algorithms allow us to investigate, in a digital model, the relationship between input variables and output results. They have been widely used in the past for forecasting future trends in finance, meteorological models and others (Bakar et al., 2009; Eck, 2017; Abbas, 2017). In order to create the initial dataset for training the ML algorithms, direct measurements of the museum environments would be needed for at least one calendar year, together with 'candidate use strategies' to be tested so that the ML system could learn drawing on the results. Nevertheless, data collection requires an extensive amount of resources, not always affordable for small museums or local bodies.

However, by performing energy simulations it is possible to create a synthetic dataset that can compensate for the absence of a sensor network and enable the initial learning phase. The simulations conducted were carried out with VPL programming tools. The need to operate on a simplified version of the H-BIM required an instrument that at the same time operated in CAD and VPL environment. The choice fell on Rhinoceros 6, GH (Grasshopper) and Dragonfly and Honeybee GH plugins for energy simulations. From the perspective of obtaining energy simulations closely as possible to reality, an analysis was carried out on the urban heat island contextual to the villa using Dragonfly (Fig.5). 
Rural

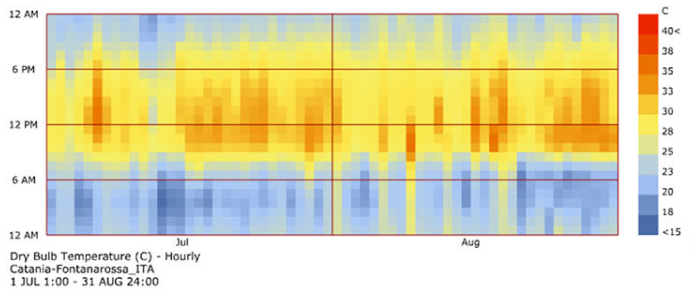

Urban
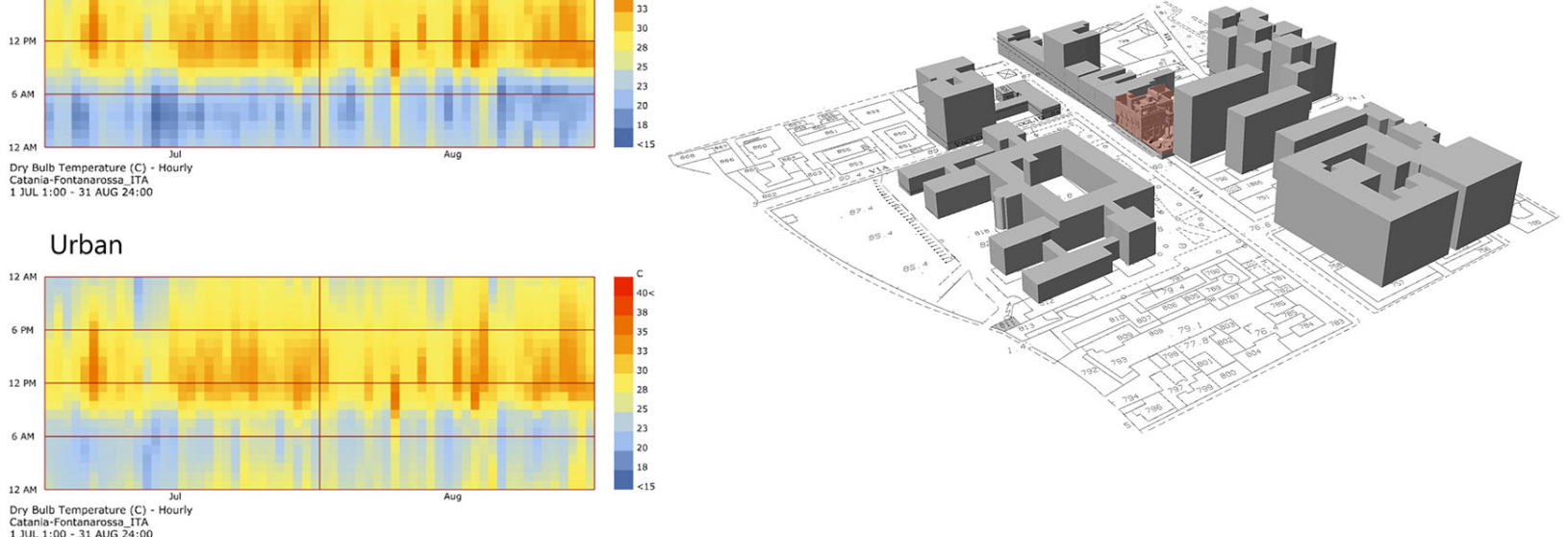

Figure 5. Urban heat island analysis based on the BIM model of the villa and 3D shapes of its urban context.

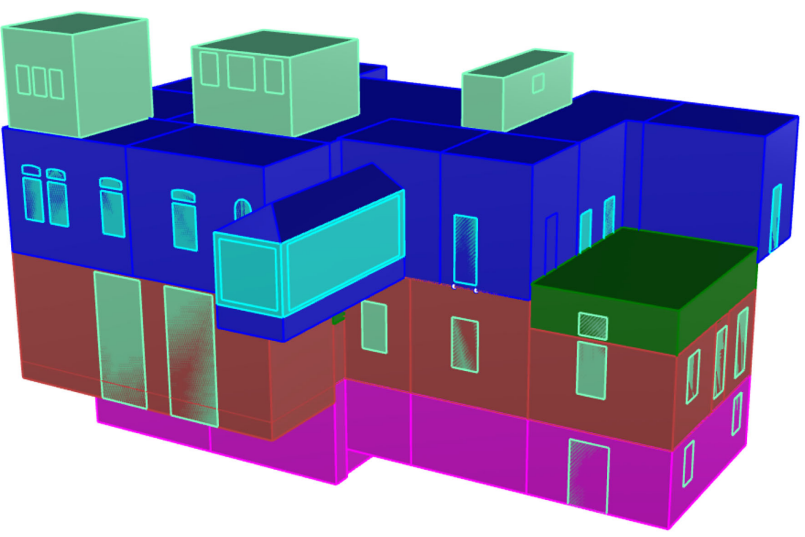

Figure 6. The simplified three-dimensional model of the villa for energy simulation.

The urban meteorological data thus generated were functional to the simulations carried out on a simplified three-dimensional model of the villa using the Honeybee plug-in (Fig. 6).

The choice of the rooms on which to carry out the analysis has considered both the conservative instance and the possibility of having different scenarios available. Therefore, the analysis has been performed in the dining room (wooden furniture), the winter garden (stain glasses sunroom) and the two adjacent rooms, which contain prints and drawings (Figg. 7-8). The thermo-hygrometric parameters required, according to the normative reference (Manoli, 2015), are explained in Table 1 (Tab.1).

Passive strategies of use considered as parameters are: utilization of natural ventilation, allowed number of visitors, HVAC system use. For each of them, it has been defined as a combination of variants that constitute the simulated configurations of use. After the fulfillment of thermohygrometric conditions simulations, data are exported and labeled. All data belonging to the days when the thermohygrometric parameters are satisfied only in a single room, as a daily average, have been excluded. Once the training dataset is labeled, then it is called up in the DSS developed in Grasshopper and two main lists of data are extracted from it.

\begin{tabular}{|l|c|c|}
\hline Room & $\mathrm{T}\left({ }^{\circ} \mathrm{C}\right)$ & $\mathrm{U}_{\mathrm{r}}(\%)$ \\
\hline Winter garden & & \\
Dining room & $\Delta \mathrm{T}<5$ & $<45$ \\
Exhibition rooms & $19-24$ & $40-65$ \\
& $19-21$ & $60-60$ \\
\hline
\end{tabular}

Table 1. Thermo-hygrometric parameters required in relation to the specific room.

One deals with the external environmental parameters (dry bulb temperature and relative humidity), while the other considers the assumed usage configurations. For the supposed conditions of use a sort of "dictionary" has been created where the keys correspond to integers $(0,1,2)$, while the variants foreseen by passive strategies are the values. Therefore, if we want to summarize using a notation related to programming languages, we get:

Adopted solutions $=\{0: 1$ st variant $;, ! 1: 2$ nd variant $; 2: 3 \mathrm{rd}$ variant?

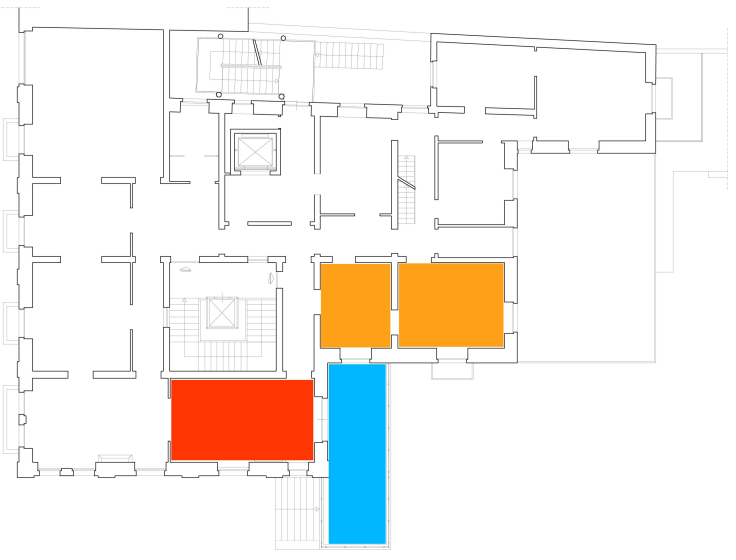

LEGEND:

Dining Room Winter Garden $\quad$ Exhibition Halls

Figure 7. Location of environments analysed by DSS. 

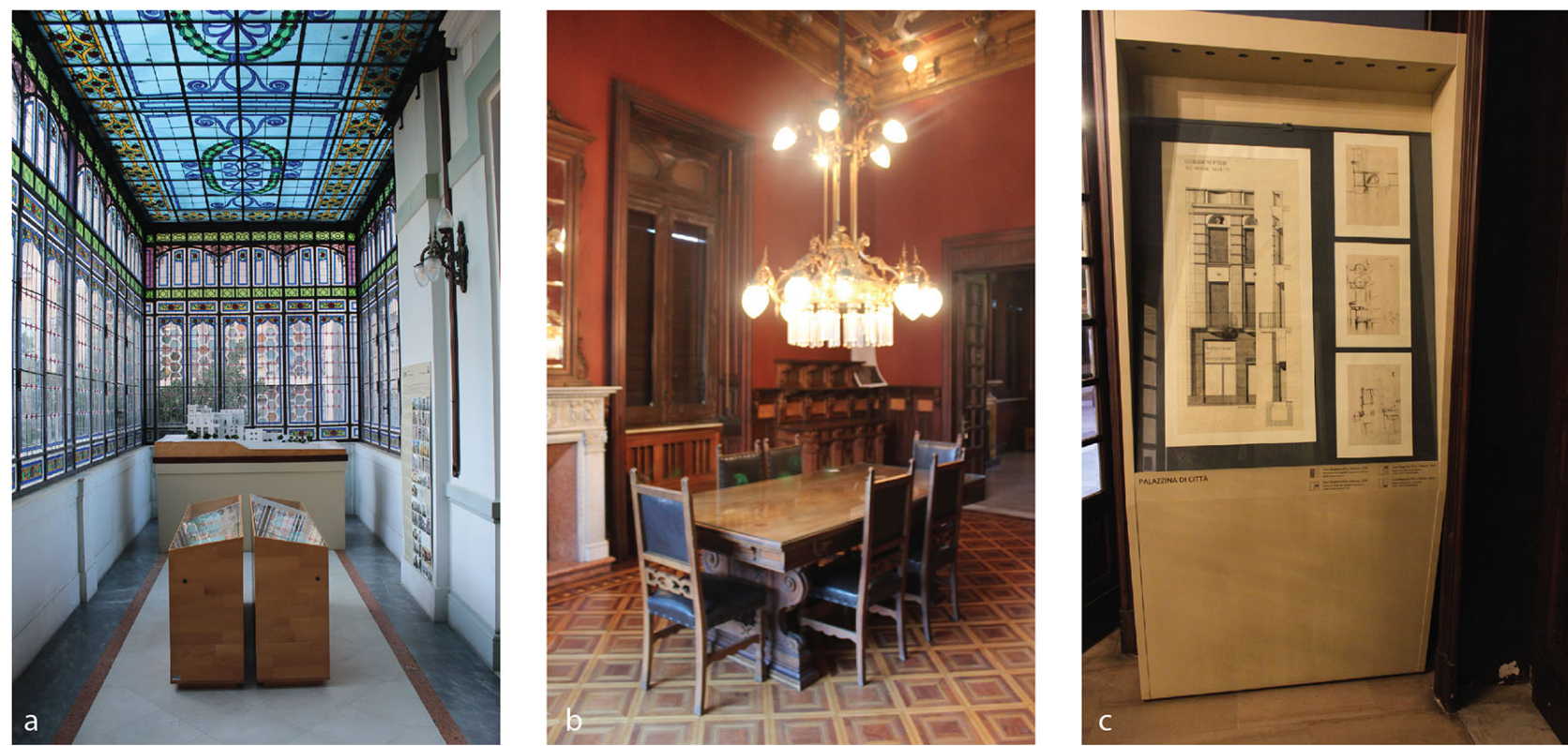

Figure 8. Rooms selected for thermo-hygrometric analysis: a) winter garden; b) Dining room; c) Exhibition hall.

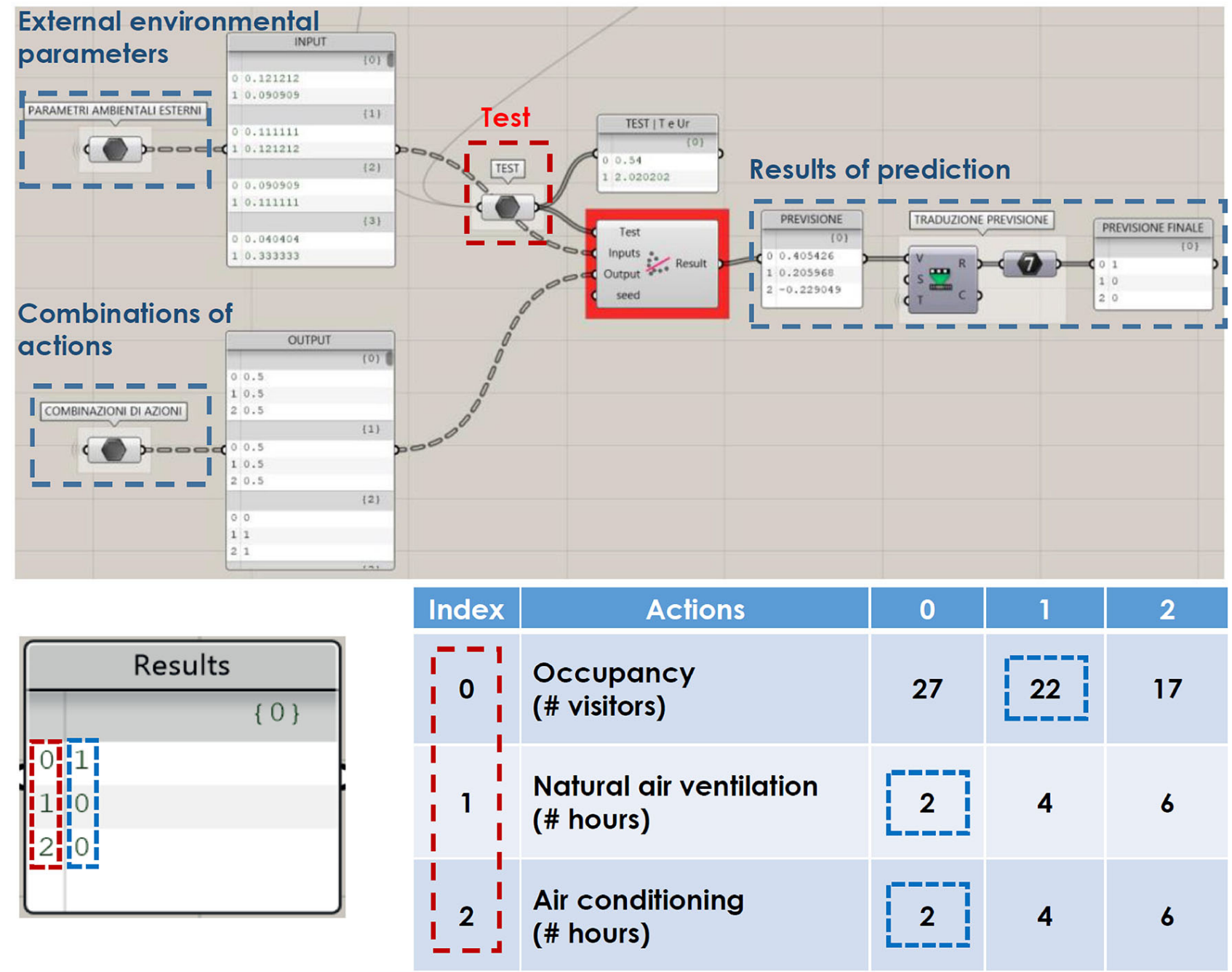

Figure 9. DSS code in Grasshopper and results of the simulation. In this example, with an outdoor temperature of $40{ }^{\circ} \mathrm{C}$ and with a relative humidity of 0.54 , the DSS suggests the combination of actions $\{1 ; 0 ; 0\}$ which (translated) means to allow access to only 22 users, to allow natural ventilation for 2 hours and 2 hours of predefined air conditioning program. 
The order in which they appear corresponds to the different fields of application (first line: occupation, second line: ventilation, third line: air conditioning system). In this way, the dataset so assembled has only successful cases (supervised learning).

The Grasshopper plugin LunchBoxML (which allows the use of multivariate linear regression component) has been used to identify the correlations between the assumed usage configurations and the satisfaction of the environmental parameters for each day. The incoming data flow in the Grasshopper component consists of two main entries (in addition to the training dataset): the inputs (temperature and relative humidity) and the outputs (configuration used). The ML algorithm will perform a linear association between the inputs and outputs. If the user wants to find out a possible usage strategy, the temperature and humidity values of the day for which the search is carried out must be entered in the input test data. In this way it is then possible to obtain the most probable correct use configuration in accordance with the values inserted as a test (Fig. 9).

\section{CONCLUSIONS}

This study has been addressed to investigate the concept of DT in relation to the management of museum collections in historical architectures and proposes the definition of HS-BIM model where AI - BIM - IoT concepts are integrated. It has also been tested a workflow which allows, thanks to the creation of a synthetic dataset, to boost the time required to gather the needed data for training the developed decision-making model and overcome the possible initial costs due to sensor installation and setup.

The expected advantages of this workflow can be envisioned in ensuring continuity in preventive conservation actions in the absence of qualified professionals and/or a monitoring system. At this first stage of testing, we applied multivariate linear regression a basic ML algorithm. This choice was also influenced by the presence of two combinations of parameters (external climatic conditions / internal prevention actions) as input and output of the code realized. In the next future, the algorithm will be implemented, and many other parameters will be taken into account.

Furthermore, our purpose is to get a DT level of maturity 5 according to Evans definition (Evans, 2019) and we can assume that at this stage of the research we have achieved a level 3. In the future we will work on the real data and on the implementation of the system in terms of AI.

Indeed, the reliability of the synthetic dataset created and used can be tested only in forward phases because it will be necessary to check, with a sensor system (for at least one year), all thermo-hygrometric parameters for each room and compare them to expected values. In addition, we will test a possible implementation of Artificial Intelligence mechanisms (such as Deep Learning) that would allow the transition to a learning system for 'attempts and errors'.

Along the time, thanks to the experience and background data, the decision-making system will improve the quality of his work.

\section{ACKNOWLEDGEMENTS}

Cettina Santagati wrote paragraphs: Introduction, Related Works. Federico Mario La Russa wrote paragraphs: HS-BIM, Methodology, Case Study, Conclusions.

\section{REFERENCES}

Abbas, O. M., 2017. Forecasting with Machine Learning. International Journal of Computer., 26(1), 184-194

Argiolas, C., Prenza, R. and Quaquero, E., 2015: BIM 3.0 Dal disegno alla simulazione, Gangemi, Roma.

Bakar, N. A. and Tahir, I. M., 2009. Applying Multiple Linear Regression and Neural Network to Predict Bank Performance. International Business Research, 2, 176-183, DOI: 10.5539/ibr.v2n4p176

Bien, Z., Bang, W. C., Kim, D. Y. and Han, J. S., 2002. Machine intelligence quotient: Its measurements and applications. Fuzzy Sets and Systems, 127(1), 3-16, DOI: https://doi.org/10.1016/S0165-0114(01)00149-X

Bolton, R., McColl-Kennedy, J. R., Cheung, L., Gallan, A., Orsingher, C., Witell, L. and Zaki, M., 2018. Customer experience challenges: Bringing together digital, physical and social realms. Journal of Service Management, 29(5), 776-808, DOI: https://doi.org/10.1108/JOSM-04-2018-0113

Brugnaro, G. and Hanna, S., 2017. Adaptive Robotic Training Methods for Subtractive Manufacturing. Proceedings of the 37th Annual Conference of the Associ ation for Computer Aided Design in Architecture (ACADIA), 164-169

Calvano, M., Cirelli, M. and Lo Turco, M., 2020. Display the Invisible. Automated Algorithms to Visualize Complex Phenomena. Proceedings of the 2nd International and Interdisciplinary Conference on Image and Imagination. IMG 2019, Alghero, 936-949

Clements-Croome, D., 2004: Intelligent Buildings: Design, Management and Operation. Thomas Telford, London.

Davis, D., 2016. Evaluating Buildings with Computation and Machine Learning. Proceedings of the 36th Annual Conference of the Association for Computer Aided Design in Architecture (ACADIA), 116-123

Eck, D. J., 2017. Bootstrapping for multivariate linear regression models. Statistics \& Probability Letters., 134, 141149, DOI: https://doi.org/10.1016/j.spl.2017.11.001

Evans, S., 2019: Beyond buzzwords: the true meaning and value of "digital twins". Link: https://www.snclavalin.com/en/beyondengineering/beyond-buzzwords-the-true-meaning-and-valueofdigital-twins

Giovannini, E. C., 2017. VRIM workflow: semantic H-BIM objects using parametric geometries. 3DModeling\& BIM. Progettazione, design, proposte per la ricostruzione., Roma, 212-229

Grieves, M., 2019: Digital Twin: Manufacturing Excellence through Virtual Factory Replication. A White Paper, LLC, Melbourne.

Kim, J., Zhou, Y., Schiavon, S., Raftery, P. and Brager, G., 2018. Personal comfort models: Predicting individuals' thermal preference using occupant heating and cooling behavior and machine learning. Building and Environment, 129, 96-106, DOI: https://doi.org/10.1016/j.buildenv.2017.12.011 
La Russa, F. M., 2019a. H-BIM and Artificial Intelligence. From the survey to the design of a DSS for villa Zingali - Tetto and the collections of the Museum of Representation. Master's Thesis, University of Catania

La Russa, F. M. 2019b. HS - BIM: Historical Sentient Building Information Model. Dn. Building Information Modeling, Data \& Semantics, 5, 17-27

Madni, A. M., Madni, C. C. and Lucero, S. D., 2019. Leveraging Digital Twin Technology in Model-Based Systems $\begin{array}{llll}\text { Engineering. } & \text { Systems, } 7, & \text { DOI: }\end{array}$ https://doi.org/10.3390/systems7010007

Manoli, F., 2015: Manuale di gestione e cura delle collezioni museali. LE MONNIER Università, Milano

Marconi, P., 1993: Il Restauro e l'Architetto - Teoria e pratica in due secoli di dibattito. Marsilio, Venezia

Pasini, D., Ventura, S. M., Rinaldi, S., Bellagente, P., Flammini, A. and Ciribini, A. L. C., 2016. Exploiting Internet of things and building information modelling framework for management of cognitive building. 2016 IEEE International Smart Cities Conference (ISC2), Trento, 1-6, DOI: 10.1109/ISC2.2016.7580817

Peng, W., Zhang, F. and Nagakura, T., 2017. Machines' Perception of Space: Employing 3D Isovist Methods and a Convolutional Neural Network in Architectural Space Classification. Proceedings of the 37th Annual Conference of the Association for Computer Aided Design in Architecture (ACADIA), 474-481

Ploennigs, J., and Schumann, A., 2017. From semantic models to cognitive buildings. Proceedings of $31^{\text {st }}$ AAAII 7 Conference on Artificial Intelligence. San Francisco, 5105-5106

Wright Steenson, M., 2017: Architectural Intelligence: How Designers and Architects Created the Digital Landscape. MIT Press

Richardson, J., 2020: What Digital Twin Technology Means for Museums. Link: https://www.museumnext.com/article/whatdigital-twin-technology-means-for-museums/

Thorndike, E. L., 1905: The elements of psychology. A. G. Seiler, New York.

Tono, A., Tono, H. and Zani, A., 2019. Encoded Memory: Artificial Intelligence and Deep Learning in Architecture in Bolognesi, C and Santagati, C (eds), Impact of Industry 4.0 on Architecture and Cultural Heritage, IGI Global, 283-305, DOI: 10.4018/978-1-7998-1234-0.ch012

Tono, A., 2018. BIMHOX: The Evolutionary Information Genes. $\quad$ Link: https://www.autodesk.com/autodeskuniversity/class/BIMHOX-Evolutionary-Information-Genes2018? pass $=$ forgeDevCon

Trento, A., Wurzer, G. and Coraglia, U. M., 2019. A Digital Twin for Directing People Flow in Preserved Heritage Buildings. 37th eCAADe and 23rd SIGraDi Conference, Porto, 561-568

Viani, F., Giarola, E., Polo, A., Vannuccini, G. and Longo, L., 2014. Decision Support System for Museum Management through Distributed Wireless Sensing. MWF2014: Museums and the $W e b$, Firenze

Wong, J. K., Li, H., and Wang, S. W., 2005. Intelligent building research: A review. Automation in Construction, 14(1), pp. 143159, DOI: https://doi.org/10.1016/j.autcon.2004.06.001

Zucker, G., Sporr, A., Kollmann, S., Wendt, A., Siafara Chaido L. and Fernbach, A., 2018. A Cognitive System Architecture for Building Energy Management. IEEE Transactions on Industrial Informatics, 14(6), 2521- 2529, DOI: 10.1109/TII.2018.2815739 